\title{
Relação família-escola: perceções de professores e pais/ encarregados de educação numa escola pública em Angola
}

\author{
Family-school relationship: perception of teachers and parents/ \\ guardians at a public school in Angola
}

\author{
Fortunato Pedro Talani Diambo ${ }^{1}$; ; Maria Luísa Branco ${ }^{1,2}$ [ \\ 'Universidade da Beira Interior (UBI); ${ }^{2}$ Universidade de Évora (CIEP-UE), Portugal
}

\begin{abstract}
Resumo
A relação família-escola é tida como fundamental para o sucesso dos alunos e das instituições escolares, influenciando as tomadas de decisão na gestão da escola. Neste artigo, analisamos as perceções de professores e pais/encarregados de educação, no que tange à relação famíliaescola, no contexto de uma escola pública com ensino primário e secundário em Angola. Para o efeito, foi desenvolvido uma investigação qualitativa, com base num caso naturalista. De acordo com os resultados das entrevistas feitas aos pais e professores, conclui-se que o envolvimento da família nas ações da escola, o acompanhamento da escolarização dos filhos, assim como a participação da família na tomada de decisão são consideradas fundamentais, contribuindo para o sucesso e o bom funcionamento das instituições escolares. Os participantes apontam, como razões principais para o pouco envolvimento da família, a falta de tempo, aliada à ocupação laboral; a falta de ações concretas e feedback positivo por parte da escola; a relação famíliaescola resumida à participação em reuniões de pais e encarregados de educação. Segundo os professores, os pais de estatuto socioeconómico mais elevado, pelo menos naquela escola, são os que menos se envolvem nas ações escolares, apresentando, os seus filhos, pior aproveitamento escolar.
\end{abstract}

Palavras-chave: Envolvimento da família; ensino primário e secundário angolano; estudo de caso naturalista; entrevistas.

\begin{abstract}
The family-school relationship is considered fundamental to the success of students and school institutions and influences decision making by school leaders. This paper analyses the perceptions of teachers and parents/guardians regarding the family-school relationship in the context of a public school with primary and secondary sections in Angola. For this purpose, a qualitative research was developed based on a naturalistic case. The results of the interviews with teachers and parents revealed that family involvement in school activities, monitoring of children's school attendance, and family participation in decision-making are considered fundamental and contribute to the success and good functioning of the school institution. Participants pointed to the lack of time and the absence of concrete actions and positive feedback from the school as the main reasons for the low level of family involvement, summarizing the family-school relationship through participation in meetings of parents and guardians. According to the teachers, the parents with the highest socioeconomic status, at least in this school, are the least involved in school actions and their children present poorer school performance.
\end{abstract}

Keywords: Family involvement; Angolan primary and secondary education; naturalistic case study; semi-structured interviews.

Como citar (APA):

Diambo, F.P.T. \& Branco, M.L. (2021). Relação família-escola: perceções de professores e pais/ encarregados de educação numa escola pública em Angola. Revista Iberoamericana de Educación, 85(2),53-71. https://doi.org/10.35362/rie8523718 


\section{Introdução}

O envolvimento da família no contexto escolar tem sido, nos últimos anos, uma problemática muito estudada por vários autores, tendo em conta a importância da participação desta instituição social no desenvolvimento e sucesso das instituições escolares, bem como no melhoramento do rendimento académico dos alunos. Alho e Nunes (2009), Bento, Mendes e Pacheco (2016), Bertan (2007), Davies (1989, 1994), Diez (1982), Diogo (2008), Fevorini (2009), Marques (1990, 1994, 1997, 2001), Oliveira e Marinho-Araújo (2010), Reis (2008), Silva (1994, 2003), Sousa e Pereira (2014) e Zassala (2012), reconhecem a necessidade e a importância do estabelecimento de uma relação escola-família mais saudável e eficaz. Apesar de a família ser uma instituição diferente da escola, com regras e objetivos diferentes, as duas partilham a importante tarefa de educar e preparar as crianças e adolescentes para a sua devida inserção na sociedade. Daí a necessidade de envolver a família na escola, ou seja, ambas as instituições não devem funcionar de forma isolada (Davies, 1989; Martins, 2008; Oliveira \& Marinho-Araújo, 2010; Silva, 1994; Sousa \& Pereira, 2014).

Em contexto africano, um estudo feito por Eshetu (2015), com o objetivo de analisar a influência da condição social e económica dos pais no rendimento escolar dos filhos na Etiópia, identificou que o envolvimento destes, nas ações escolares, contribui para a promoção de uma boa parentalidade e para a criação de um ambiente familiar seguro e estável traduzido um acompanhamento mais criterioso da atividade escolar dos filhos. Este envolvimento tem influência no aproveitamento académico dos mesmos, contribuindo, ainda, para uma melhor inserção na sociedade.

O envolvimento da família na escola é considerado como sendo uma preocupação necessária e legítima, e não uma opção extra de que a escola pode prescindir. É uma componente importante para o desempenho ideal das instituições escolares, assim como para a garantia de uma educação socialmente aceite (Bento et al., 2016; Reis, 2008; Silva, 2003; Sousa \& Pereira, 2014).

Um estudo feito por Sousa e Pereira (2014), com o objetivo de analisar a perceção dos encarregados de educação e dos professores sobre a relação escola-família, concluiu que os pais apontam a falta de tempo, os horários da escola não adequados ou compatíveis com o seu tempo laboral, 
as dificuldades em ajudar os filhos em casa, a falta de competência para participar direta e de forma ativa na escola, como estando na base do seu pouco envolvimento. Já os professores apontam o desinteresse dos pais no processo educativo dos seus filhos, bem como uma ideia desadequada sobre o que julgam ser o acompanhamento adequado em casa (Bertan, 2007; Diambo, 2014; Lopes, 2014). Bertan (2007) identificou, ainda, que os pais muitas vezes só são chamados ou convocados à escola, quando os seus filhos estão com problemas nos estudos, ou em caso de comportamento problemático.

Um estudo realizado por Rocha (2009), numa escola secundária em Cabo-Verde, com o objetivo de analisar o envolvimento parental na escola, e como ele é percecionado por professores e pais, identificou que a escola somente abre as suas portas aos pais no início do ano letivo, para informar as famílias sobre a programação da atividade anual. A escola parece preferir estabelecer intercâmbio com instituições de ação humanitária, em detrimento das famílias. Estas são, algumas vezes, convidadas a participar em alguns processos decisórios (comissões disciplinares e conselho de escola), mas sem efeitos práticos. Acresce a isto que a participação dos pais, na escola de seus filhos, é determinada pelo conselho diretivo e por alguns professores, dentro dos interesses da escola, ou seja, os pais são convidados a participar se a escola achar necessário (Rocha, 2009).

Diambo (2014), na sequência de uma investigação feita numa escola pública do ensino primário e do $1^{\circ}$ ciclo do ensino secundário, na cidade do Dundo, em Angola, concluiu que os pais não se envolvem muito na vida escolar dos seus educandos. Entre as principais razões destacam-se a falta de tempo e estes acharem que os seus filhos são bons alunos e não têm problemas com a escola.

Considerando a importância da relação entre a família e a escola evidenciada pela literatura, propomo-nos, no contexto do presente artigo, aprofundar o estudo sobre a perceção dos pais/encarregados de educação e professores sobre a relação família-escola, no contexto de uma escola pública em Angola, procurando responder à questão de investigação: De que forma os pais e professores percecionam a problemática do envolvimento da família na escola, no contexto de uma escola pública em Angola? 


\section{Método}

Tendo em conta a questão colocada, optámos por um estudo qualitativo. Segundo Vilelas (2017), "a investigação qualitativa é uma forma de estudo da sociedade que se centra no modo como as pessoas interpretam e dão sentido às suas experiências e ao mundo em que elas vivem" (p. 163). A investigação qualitativa é a que melhor se ajusta a estudos que pretendem compreender as intenções, crenças, opiniões, perceções, representações e perspetivas subjacentes às ações realizadas pelos seres humanos, em relação com os outros contextos em que e com que interagem (Amado, 2014; Vilelas, 2017).

O estudo foi concretizado mediante a opção por um estudo de caso naturalista, conduzido num contexto real. De acordo com Vilelas (2017),

Aadoção dos estudos de caso é adequada quando são propostas questões de pesquisa do tipo "como» e "porquê", e nas quais o pesquisador tem um fraco controlo de uma situação que, pela sua natureza, está inserida em contextos sociais (p. 197).

\subsection{Participantes}

Foram selecionados intencionalmente, em coordenação com os gestores da instituição escolar visada para a presente investigação, 20 informantes. Destes, 10 informantes fazem parte do corpo docente e os outros 10 são pais e encarregados de educação. Relativamente aos docentes, trabalhámos com o diretor geral, o subdiretor pedagógico, 3 coordenadores de turmas e 5 professores sem nenhuma função de chefia. Da parte da família, trabalhámos com 10 pais e encarregados de educação, 5 de cada género e de estatuto social diferente (médio e baixo).

\subsection{Instrumentos}

Tendo em conta o tipo de investigação realizada, usámos como instrumento para recolha de dados a entrevista semiestruturada. A entrevista é considerada por vários autores como sendo a técnica rainha dos estudos qualitativos (Afonso, 2014; Marconi \& Lakatos, 2003).

A opção pela entrevista semiestruturada como instrumento de recolha de dados, prende-se pelo facto de a sua construção estar baseada nas questões orientadoras da investigação, permitindo uma gestão mais controlada 
e dirigida da entrevista por parte do investigador, e por ser uma modalidade de entrevista que permite aos entrevistados desenvolver o seu ponto de vista sobre um assunto em particular (Afonso, 2014).

\subsection{Técnica de análise de dados}

Segundo Bogdan e Biklen (1994), "a investigação qualitativa envolve pegar nos objetos e acontecimentos e levá-los ao instrumento sensível da sua mente de modo a discernir o seu valor como dado" (p. 200). No âmbito de uma investigação qualitativa e como referido por Bardin (2016), "o recurso à análise de conteúdo para tirar partido de um material dito qualitativo, é indispensável..." (p. 89).

A análise de dados da presente investigação foi efetuada mediante as seis fases referidas por Marshall e Rossman (1999, citados por Afonso, 2014, p. 128): "a organização dos dados, a produção de categorias, temas e padrões, a codificação dos dados, a testagem das interpretações que vão emergindo, a busca de explicações alternativas e a produção do texto final". Assim sendo:

Na primeira fase (organização dos dados), procedemos à leitura do material obtido durante o trabalho de campo e à sua organização, de modo a facilitar a sua consulta. Ou seja, "a organização física da informação, através da identificação e agrupamento de textos, paginação, numeração de linhas ou parágrafos e criação de índices" (Afonso, 2014, p.128).

Na segunda fase (produção de categorias, temas e padrões), realizou-se uma interpretação do processo, que nos conduziu ao desenvolvimento da categorização do material disponibilizado, centrada na "interação entre os eixos da análise, que permitiram a operacionalização do dispositivo de recolha de dados, as regularidades, padrões e tópicos que emergem da leitura analítica dos textos" (Afonso, 2014, p. 129).

Para esta investigação, optámos por um sistema de categorização mista, pois foram criadas categorias a partir da revisão bibliográfica previamente realizada (sistema de categorias a priori ou análise de conteúdo dedutiva), assim como a construção de algumas categorias que emergiram da análise dos dados (análise de conteúdo indutiva). Importa realçar que a categoriza- 
ção foi feita tendo em atenção as seis regras fundamentais da codificação, propostas por Amado (2014), de formas a garantir consistência ao sistema de categorias e da análise efetuada, que são:

- Exaustividade (abranger no sistema de categorias elaborado, todos os itens relevantes para o estudo, presentes no corpo documental);

- Exclusividade (cada unidade de registo será exclusivamente enquadrada em uma só categoria);

- Homogeneidade (cada categoria fará referência a uma única dimensão de análise);

- Pertinência (o sistema de categorias estará ajustado ou em concordância com o corpus em análise, e com a problemática e o objetivo da investigação);

- Objetividade (clarividência na elaboração de cada categoria, evitando a subjetividade e a ambiguidade);

- Produtividade (não limitada somente à interpretação imediata dos documentos, mas que permita, também, análises férteis, capazes de nos levar a um nível de teorização).

Na terceira fase (codificação dos dados), fez-se a atribuição de um código para cada categoria e, de seguida, todo o material empírico em nossa posse foi codificado em conformidade à referida categoria antes definida, dando origem a um corpus de informação, desenvolvido e devidamente organizado em função dos objetivos da pesquisa (Afonso, 2014).

Na quarta fase (testagem das interpretações) realizou-se uma análise lógica e analítica da informação já estruturada, assim como foram estabelecidas possíveis relações entre o material empírico, de forma a avaliar o nível de coerência do mesmo, comparativamente com a fundamentação teórica da problemática em estudo. Como referido por Afonso (2014):

À medida que a informação se estrutura por categorias e unidades de sentido, o investigador vai ensaiando a identificação de relações lógicas entre os aspetos substantivos do material empírico, avaliando a coerência da lógica interpretativa em construção e a pertinência e relevância dos dados disponíveis em relação às diversas pistas interpretativas (p. 130). 
Na quinta fase (busca de explicações alternativas), analisou-se o material elaborado, assim como, os procedimentos utilizados, o que permitiu uma visão mais ampla dos elementos que favorecem, ou não, a interpretação antes feita, para encontrar explicações alternativas caso faça sentido. Segundo Afonso (2014) esta é a fase "em que o investigador deve desafiar a coerência e solidez da sua construção interpretativa procurando deliberadamente os dados que possam enfraquecê-la ou contradizê-la" (p. 130).

Na sexta fase (produção do texto final), realizou-se a escrita do texto interpretativo, com intuito de dar resposta à questão orientadora desta investigação.

\section{Resultados}

Apresentamos, de seguida, os resultados da análise de conteúdo das entrevistas, por categoria e subcategoria, começando pelas entrevistas dos pais/EE e continuando com a dos professores.

\subsection{Conceção dos pais sobre o envolvimento da família na escola}

Quanto ao estado da relação família-escola

Os pais e encarregados de educação reconhecem a fraca relação famíliaescola, porém apontam o pouco interesse de ambas as partes e/ou não terem feito o suficiente para que aquela acontecesse conforme o desejado.

A este respeito, o PEE9 diz:

Não existe uma relação tal, entre a escola e os encarregados, porque falta mais um "bocadinho" de interesse tanto da parte dos encarregados, assim como da parte da própria escola, promover de forma constante alguns encontros para irem informando os encarregados, tudo que tem sido o dia-a-dia das crianças naquela escola. (...) só ir à escola e voltar, se calhar pode não ser o suficiente (...) (p. 36).

Por outro lado, o PEE4 afirma existir em alguns casos ação coerciva da escola para com os alunos, sem consulta prévia dos pais e encarregados de educação, como podemos ler de seguida: 
Eu acho que há ainda muita coisa que deve mudar (...), porque na maioria das vezes, os educandos venham mais com reclamações da escola (...), já não há aquele hábito da escola em que quando o educando comete, mandarem chamar o seu encarregado... as vezes é atuação direta da coerção da escola sobre o estudante ou educando (p. 16).

\section{Quanto à influência na tomada de decisões}

Sobre a influência da família na tomada da decisão, os pais e encarregados de educação, na sua maioria, circunscrevem esta situação à emissão de opiniões nas reuniões e/ou encontros que têm tido com a escola. Porém, afirmam que é possível influenciar as decisões da escola se estes (PEE) participarem mais.

A título de exemplo, é referido por PEE3: “(...) aproveitamos (...) expor as nossas opiniões nas reuniões convocadas pela Direção da escola, (...) são algumas opiniões que nós demos, e esperamos a prática" (pp. 12-13).

A este respeito, o PEE10 diz: "Vejamos que situações há, em que a Direção notifica certos encarregados e não aparecem, (...). Logo, a Direção toma a decisão sozinha" (p. 41).

\section{Quanto ao envolvimento e acompanhamento dos pais na escolarização dos filhos e sua influência na ação da escola}

O acompanhamento dos pais na escolarização dos filhos foi tido como de grande importância, pela maioria dos entrevistados, na medida em que evita comportamentos menos bons dos filhos, promove uma intervenção positiva dos pais e encarregados de educação em relação à escola, assim como favorece o alcance de uma escola de sucesso. Como pode-se ler, a título de exemplo:

(...) os encarregados ausentes fazem com que simplesmente a educanda viva por si só (...), vai à escola quando quer uma vez ou outra, isso pode contribuir negativamente, porque a escola pode tomar várias decisões quer positivas, quer negativas para essa educanda. (...) é sempre importante que os pais estejam (...) com conhecimento tudo quanto se passa com a sua educanda (...), para não interferir de forma negativa no processo (PEE9, p. 37).

A forma como a família faz o acompanhamento escolar do filho pode influenciar, negativa ou positivamente, o funcionamento da escola, como refere, por exemplo, o PEE10: 
(...) a escola encontra-se numa comunidade, então nós os moradores já fizemos também parte daquela instituição direta ou indiretamente (...), então as famílias venham até certa medida influenciar o sucesso da Direção como também o insucesso, tudo dependerá da forma como nós vamos nos (...) envolver com a Direção da escola (PEE10, p. 41).

Ideia partilhada por PEE2, quando refere: “(...) se a família for atenta ao processo de formação do seu filho, penso que não poderá criar grandes problemas à Direção da escola" (p. 7).

\section{Quanto à responsabilidade familiar e/ou social no acompanhamento da educação da criança}

A convicção expressa pela maioria dos pais e encarregados de educação é a de que os pais têm a responsabilidade de acompanhar a vida escolar dos filhos. "(...) um pai preocupado tem que saber como é que o filho está indo na escola, e como é que ele está a se desenvolver, se o filho está aplicado ou não (...)" (PEE1, p. 3).

Existem pais e encarregados de educação que não se preocupam tanto em acompanhar a vida escolar dos seus educandos, limitando-se a deslocar-se à escola no final do ano letivo, delegando, na maioria das vezes, grande parte das suas responsabilidades à direção da escola, e culpando consequentemente esta, na eventual ocorrência de qualquer situação menos agradável com o seu educando, como refere, a título de exemplo, PEE3:

(...) há aqueles pais, desde o início do ano letivo não fazem acompanhamento dos filhos, depois chega um período em que as aulas estão no meio (...), o filho, às vezes, não tem nome na lista, depois aparece lá, fica um bocadinho constrangido (...) é claro que naquele momento ele não vai dizer que a Direção da escola está organizada (...) vai sempre criar uma base para dizer que a escola está desorganizada, nunca esteve organizada, a Direção é péssima (pp. 11-12).

Alguns pais e encarregados de educação entrevistados sublinham o seu papel de educador para a socialização desejada do filho, de tal forma que o bom comportamento que o filho apresenta no seio familiar se reflita na sociedade. É o caso de PEE4, quando refere:

(...) as pessoas devem ser bem-educadas, bem instruídas (...), da mesma forma de como olham para um pai, uma mãe ou um irmão mais velho, que fossem tratar as outras pessoas do mesmo modo, (...) e fazer com que a nossa presença como família, o nosso bom nome na sociedade, reflita sobre os seus atos para com outras pessoas (p. 17). 
Também PEE2 afirma que a família tem responsabilidades sociais na consciencialização da criança,

(...) repare que estamos a falar de meninos de pouco menos de oito, nove, dez, onze anos, pouco ou nada sabem do mundo académico, do mundo envolvente à escola... é lógico que os pais se envolvam para catapultar a consciência dos meninos ainda nessa tenra idade, para que de facto sejam o garante do futuro que é o homem do amanhã (p. 5).

\subsection{Conceção dos professores sobre o envolvimento da família na escola}

Quanto ao estado e pertinência da relação família-escola

Quanto ao estado da relação família-escola, a maioria dos professores considera que é uma relação insuficiente, como a título de exemplo é expresso por P8:

(...) o envolvimento da família no contexto escolar tem sido muito fraco, (...) o envolvimento é só na matrícula, (...) se calhar pagamento de uma ou outra comparticipação financeira para o estudante, (...) senão, não existe um envolvimento total da parte dos parentes quanto aos estudantes (pp. 77-78).

Sobre a pertinência dessa relação, alguns professores afirmam que, se se estabelecesse uma boa relação com a família, isso permitiria que esta, para além do rendimento escolar do educando, tomasse conhecimento de como a escola está a funcionar. Caso de P5, “(...) se tivéssemos uma relação com eles seria muito bom, porque (...) estariam a acompanhar (...) o desempenho e o comportamento acima de tudo da instituição e saber como está (...) o seu educando" (pp. 64-65).

Quanto ao envolvimento e acompanhamento dos pais nos trabalhos escolares dos filhos e sua influência na ação da escola

Os professores entrevistados são quase unânimes em afirmar que o envolvimento dos pais e encarregados de educação em atividades escolares dos filhos influencia, em grande medida, o bom funcionamento da escola, como nos afirma, a título de exemplo, P6 "(...) os pais e encarregados de educação, são parceiros de apoio à Direção da escola, há certas decisões que a Direção toma, (...) com o apoio ou a sugestão dos pais e encarregados de educação" (p. 69). A este respeito, P7 afirma: "(...) se a família se envolver no acompanhamento, (...) participa nas atividades escolares 
ou extraescolares quando são convocados, e ter uma relação direta (...) segundo os documentos orientadores, acho que isso poderia influenciar muito no desenvolvimento da escola" (p. 74). P4 afirma que, "(...) um pai ausente na vida escolar do filho (...), empobrece a própria instituição” (p. 60).

Alguns professores entrevistados defendem a partilha de responsabilidades educativas, pois pode proporcionar uma relação família-escola mais saudável e, consequentemente, contribuir para o desenvolvimento da instituição escolar, como referido à título de exemplo por P7, "(...) a escola faz a sua parte que é ensinar (...) os pais também vão sempre sensibilizando, educando os (...) seus filhos para que possa haver uma relação direita e o desenvolvimento da própria escola" (P7, p.74).

Na mesma linha, P10 refere que o envolvimento e acompanhamento da família, na atividade escolar do aluno, tem um carácter importante, pois pode contribuir para a identificação de fatores que estejam a interferir na compreensão dos conteúdos ministrados na escola por parte do aluno, uma vez que existem vários fatores, que ocorrem no contexto familiar, passíveis de influenciar, direta ou indiretamente, o aproveitamento escolar do aluno.

(...) os pais ajudariam os professores, porque tem alguns filhos que não se adaptam bem aos conteúdos (...) que se dá aqui, porque os alunos não são acompanhados pelos pais, (...) têm alguns problemas... tem algo que aconteceu em casa, (...) nós (...) os professores não sabemos, e não temos como suprir estes problemas (P10, p. 88).

A este respeito, P2 refere, ainda, que o envolvimento e acompanhamento da família na atividade escolar do aluno é importante, pois pode facilitar a atividade do professor ajudando com explicações aos filhos em casa, na medida em que o tempo de que dispõem os professores nem sempre é compatível com a quantidade da matéria a lecionar, como pode-se ler de seguida:

(...) eu estou a lecionar sétima classe e vejo que muitos alunos não sabem escrever, (...) tenho a certeza de que se a família estivesse mais preocupada, (...) se os pais colaborassem em casa dando explicação aos seus filhos, (...) isto não estaria a reinar muito, (...) porque eu tenho quarenta e cinco minutos para lecionar uma aula, e às vezes eu posso não conseguir atingir os (...) objetivos (P2, p. 51).

Para P1, o envolvimento dos pais e encarregados de educação pode ter, ainda, grande influência no comportamento do aluno na sala de aula, 
(...) toda criança se sente bem quando (...) os pais estão envolvidos na educação, (...) na vida diária dele (...), ela sente-se confortável e seguro (...). (...) é fácil a criança estar mais atenta na aula, o desenvolvimento dele muda, (...) é uma criança diferente, alegre, é fácil ela dominar ou interpretar muito bem os conhecimentos que são ensinados (P1, p. 47).

\section{Responsabilidade social e/ou familiar no acompanhamento da educação da criança}

Metade dos entrevistados reconhece a responsabilidade social da família no acompanhamento do educando, pois constitui o núcleo básico e fundamental para a educação da criança, como foi referido por P7: "(...) a família é o núcleo principal da formação de um indivíduo, não só a escola" (p. 74). A família regula a atitude comportamental da criança dentro e fora do contexto familiar, referindo alguns professores que os alunos tendem a apresentar, em muitos casos, um comportamento duplo, como refere a título de exemplo P2,

(...) o aluno em casa, é outra coisa e fora de casa, também é outra (...)! Muitos alunos comportam-se mesmo mal, (...) se os encarregados estivessem sempre aqui a par e passo quando puderem, nos ajudaria. (...) o envolvimento deles (...) é sempre bom (P2, p. 51).

A este respeito, P6 afirma: “(...) O estudante tem duas vidas (...), vida académica e vida social, e o pai tem de fazer acompanhamento na vida social e na vida académica para tudo correr bem e dar certo" (p. 71).

\section{Envolvimento dos pais nas tomadas de decisão}

A maioria dos professores entrevistados refere não haver envolvimento dos pais e encarregados de educação nos órgãos de tomada de decisão, pois estes limitam-se a dar a sua opinião nas reuniões de pais e encarregados de educação, convocadas pela escola, como refere a título de exemplo P9: "(...) geralmente as opiniões são dadas nos encontros com a comissão ou com os encarregados de educação" (p.82).

Os professores reconhecem, ainda, que as opiniões dadas pelos pais nem sempre são tidas em consideração por parte da escola, como refere P4: "Eles participam uma vez a outra e dão a sua opinião, mas a concretização nem sempre é efetivada" (p.57). 
A escola, muitas vezes, toma decisões sem consultar os pais e encarregados de educação, como refere, por exemplo P5: “(...) às vezes, nós temos tomado decisões, só a Direção da escola, sem a participação dos encarregados" (p.62).

Alguns professores reconhecem que as decisões tomadas pela escola, sem consultar ou sem a participação dos pais, tendem a afetar negativamente as famílias, como refere a título de exemplo P9: "geralmente quando a família não colabora com a escola, as decisões da escola praticamente afetam a família" (p.81).

Condição socioeconómica da família e sua influência na relação famíliaescola

Apesar de grande parte dos professores entrevistados reconhecerem a condição socioeconómica da família como fundamental, não consideram, contudo, ser condição suficiente para uma boa relação família-escola, como refere, a título de exemplo, P7:

Em parte, a condição socioeconómica é fundamental, porque tendo em conta o lugar também onde está situada a nossa escola, a distância em si também se conta, (...) um pai que socialmente tem pouco rendimento económico, é difícil frequentar a escola mais vezes por motivo do próprio transporte. (...) acontece que os pais que têm menos possibilidades e os pais que têm, quase todos estão no mesmo nível, não aparecem com frequência na escola! (...) A condição económico-social não é cem por cento para uma boa relação família-escola (p. 76).

A este respeito, P6 afirma mesmo “(...) as pessoas com condição social meio precária são as que mais estão aqui na escola (...). Os ricos até muitas das vezes não dão importância ao professor, (vou falar o quê com ele!...), (...) mandam sempre outra pessoa" (p. 68).

Para alguns professores, o envolvimento da família na escola, é também uma questão de educação familiar, independentemente da condição socioeconómica da mesma, e da organização da própria escola, como referido, a título de exemplo, por P8:

(...) há encarregados com pouca possibilidade financeira, mas que já foram educados de que é necessário acompanhar o seu filho, e também há instituições que criam meios e formas de os encarregados estarem envolvidos e que eles vão, (...) estando bem economicamente ou não, (...) então isso passa talvez pela organização da própria escola (pp. 81-82). 


\section{Discussão}

Os professores e pais/encarregados de educação reconhecem, e manifestam, a necessidade e o desejo de uma relação família-escola mais próxima e saudável. A sua efetivação prática não é, contudo, muito notória. Resultados convergentes com os estudos desenvolvidos por grande parte de investigadores ligados à problemática da relação família-escola, como, por exemplo, Bertan (2007); Dessen (2010); Diambo (2017); Dias (2005); Eshetu (2015); Fevorini (2009); Marques (2001, 2002).

O envolvimento da família no contexto escolar contribui para a melhoria do rendimento escolar do educando e, quiçá, para o desenvolvimento harmonioso da criança, de acordo com Marques (2002):

O desenvolvimento e a educação da criança dependem sobretudo do esforço comum das esferas sobrepostas que constituem o mundo da criança. Quando estas esferas comunicam e se relacionam de forma positiva, cria-se um ambiente ecológico favorável ao desenvolvimento. Quando estas esferas estão de costas voltadas, prosseguem objetivos opostos ou comungam valores conflituantes, estamos perante um ambiente que dificulta o desenvolvimento da criança (p.3).

É também este o entendimento de PEE3, quando refere: "O envolvimento da família na escola, (...) é benéfico para os dois lados (...), isso porque ajuda os familiares a acompanharem o desenvolvimento do filho, e a escola se na verdade está mesmo a desempenhar o seu papel" (PEE3, p.11). Por outro lado, os professores manifestam o desejo e a necessidade de se estabelecer uma relação família-escola mais próxima, mas, na opinião destes, a família só se desloca à escola na eventualidade de existir algum problema que requer a presença do pai e encarregado de educação. Como referido por P5: “( ...) a relação seria uma relação de parceria e colaboração, mas só que eles só aparecem quando têm um problema" (p. 64).

A este respeito, Dessen e Polonia (2007) consideram a família e a escola como sendo os dois contextos fundamentais do desenvolvimento humano nas sociedades contemporâneas. Desta constatação resulta a necessidade de se ir estabelecendo políticas conducentes a uma aproximação entre estas duas instituições, de modo a que reconheçam os seus papéis, no tocante aos processos de desenvolvimento do ensino e aprendizagem do aluno e à sua contribuição nos variados níveis de desenvolvimento e da sociedade em geral. 
Os pais e encarregados de educação acusam a escola de não se preocupar com a família quando tudo vai bem da parte do aluno, o que inibe ou desincentiva o envolvimento da família no contexto escolar. Caso de PEE3, quando refere:

\begin{abstract}
A escola só convoca quando acontece algo ruim... se o filho não cumpriu as regras, não fez a limpeza... recebem a bata, recebem a mochila!... Agora quando o filho tem êxito, a escola nunca convocou os pais para dizer olha, aperta o teu filho porque ele é bom, (...) tem vontade... nunca recebi essa notificação!... E eu me sentiria bem (...), ser convocada e ouvir que o meu filho é um excelente aluno (p. 13).
\end{abstract}

Estes resultados estão de acordo com os de Bento et al. (2016), Oliveira et al. (2010) e Reis (2008), segundo os quais os principais fatores que interferem no envolvimento da família no contexto escolar são, segundo os pais, a falta de comunicação, a atribuição de culpa à família sobre o insucesso escolar do aluno e a chamada dos encarregados de educação somente quando o filho é indisciplinado.

Na opinião de alguns professores, a escola, na maioria das vezes, toma as decisões sobre os alunos de forma unilateral, estando de acordo ou não com a família. As reuniões de pais e encarregados de educação convocadas pela escola têm sido o meio utilizado pela família para influenciar a decisão da escola através de opiniões. Pelo que os professores reconhecem a falta de incentivo por parte da escola em promover mais o envolvimento da família no contexto escolar, conforme relatado por P3, “(...) falta (...) também do nosso lado, (...) falta ainda muito para incentivar os pais, (...) nós também temos (...) que ser mais criativos, (...) melhorar alguns aspetos, que faça com que os pais também venham" (p. 58)

Quanto à condição económica/financeira e social das famílias, os professores julgam ser um fator a ter em conta, mas não tão significativo a ponto de influenciar a não ocorrência do envolvimento da família no contexto escolar, pois, no entender destes, existem famílias social e economicamente estáveis, mas que, ainda assim, não se interessam com o acompanhamento escolar do filho, muito menos estabelecem uma relação de proximidade com a escola de seu filho, podendo os seus filhos apresentar menor aproveitamento escolar, conforme referido por P5, "os pais de nível social alto são os que têm educandos mais "vaidosos", (...) quando sabem que têm um nível social ou económico muito avançado, estes é que têm pouca participação e desempenho na escola" (p. 66). 
P8 reforça: “(...) há pessoas com uma estabilidade financeira ou económica muito boa, e que nem querem saber também! (...) isso depende muito, mas é um dos fatores preponderante que pode favorecer mais ou menos no envolvimento da família na escola" (P8, p. 82). Estes resultados convergem com o estudo de Lopes (2014) sobre interação família-escola, feito em duas escolas da capital de Angola (Luanda), onde identificou que os pais e encarregados de educação da classe média-alta, e de entre estes até os que possuem formação superior, são os que menos interagem com a escola. Porém, contrapõem-se aos obtidos pela grande maioria dos investigadores sobre a problemática da relação família-escola, por exemplo, os resultados obtidos por Bertan (2007), Eshetu (2015), Fevorini (2009), Reis (2008), Silva (2003), Sousa e Pereira (2014), onde os pais de baixo estatuto social e económico foram identificados como sendo os que menos se envolvem nas ações escolares dos educandos, apesar da importância que atribuem à escolaridade dos filhos.

Estudo feito por Eshetu (2015) em Dessie Town, Etiópia, no intuito de analisar a influência da condição social e económica dos pais no rendimento escolar dos filhos, constatou que os alunos de pais cujo estatuto social e económico é médio ou alto têm melhor aproveitamento escolar em comparação com os filhos de pais de estatuto social e económico baixo. De acordo com Fevorini (2009), "os pais da classe social média não delegam para a instituição a formação de valores fundamentais de sociabilidade à escola" (p. 70).

\section{Conclusão}

A relação família-escola é fundamental, devendo ser aprofundada, pois contribui para melhorar o aproveitamento escolar dos alunos e o sucesso das instituições de ensino. O acompanhamento das atividades escolares dos filhos em casa, as deslocações das famílias à escola, assim como as visitas domiciliárias, previamente agendadas pela escola, constituem boas práticas, que fomentam uma melhor relação família-escola.

O facto de a escola não procurar as famílias quando os alunos não apresentam problemas, desincentiva ou inibe a iniciativa dos pais e encarregados de educação, de visitar regularmente as escolas onde estudam os seus 
filhos. Neste estudo, reconhece-se a necessidade de a escola se preocupar com as famílias de todos os alunos, incluindo aqueles que não evidenciam problemas de indisciplina ou de rendimento académico.

Acondição económica/financeira e social das famílias é um elemento a ter em conta no estabelecimento de uma boa relação família-escola. Não constitui, porém, no caso deste estudo, o principal obstáculo da não ocorrência da relação família-escola, no caso das famílias cujo estatuto social e económico/ financeiro é baixo. A vantagem das famílias com estatuto social e económico/ financeiro médio/alto, reside na maior facilidade de deslocação às escolas dos filhos, e na satisfação mais efetiva das necessidades destes. No contexto onde foi desenvolvido este estudo, constatou-se que, os pais de estatuto social e económico/financeiro médio/alto, são os que menos frequentam ou visitam a escola dos filhos, contrastando com as conclusões da grande maioria da literatura especializada sobre o assunto. Possivelmente, julgam estes pais e encarregados de educação que, colmatando as necessidades dos filhos, não precisam de se deslocar àquele contexto.

\section{Referências}

Afonso, N. (2014). Investigação naturalista em educação: Um guia prático e crítico. V. N Gaia, Portugal: Fundação Manuel Leão.

Alho, S. M. \& Nunes, C. (2009). Contributo do diretor de turma para a relação escola-família. Revista Educação, 32(2), 150-158. Recuperado de https://bit.ly/3bqqjvj.

Amado, J. (2014). Manual de investigação qualitativa em educação. Coimbra, Portugal: Imprensa da Universidade de Coimbra.

Bardin, L. (2016). Análise de conteúdo. Lisboa, Portugal: Edições 70, Lda.

Bento, A. V., Mendes, G. R. \& Pacheco, D. (2016). Relação escola-família: Participação dos encarregados de educação na escola. Investigação qualitativa em educação/atas de CIAIQ2016, 603-612. Madeira, 1. Recuperado de http://bit.ly/3caoRwj.

Bertan, L. (2007). A relação escola-família: Um espaço negado aos pais? Colloquium Humanarum, 3(2), 1-11. https://doi.org/10.5747/ch.2005.v03.n2/h023.

Bogdan, R. \& Biklen, S. (1994). Investigação qualitativa em educação: Uma introdução à teoria e aos métodos. Porto, Portugal: Porto Editora.

Davies, D. (1989). As escolas e as famílias em Portugal, realidades e perspetivas. Lisboa, Portugal: Livros Horizonte.

Davies, D. (1994). Parcerias pais-comunidade-escola. Inovação, 7(3), 377-389. Lisboa, Portugal: Instituto de Inovação Educacional. 
Diambo, F. P. T. (2014). Rendimento acadêmico dos alunos e papel dos pais/encarregados de educação em Angola: O caso de uma escola do ensino primário e do $I^{\circ}$ ciclo do ensino secundário (Dissertação de Mestrado). Universidade de Évora.

Diambo, F. P. T. (2017). Relação Família e Escola: Rendimento escolar dos alunos. Luanda, Angola: Eco7.

Dias, M. (2005). Como abordar... A construção de uma escola mais eficaz. Porto, Portugal: Areal Editores, S.A.

Dessen, M. A. \& Polonia, A. C. (2007). Família e escola como contextos de desenvolvimento humano. Paidéia, 17(36), 21-32. Recuperado de https://bit.ly/3ekUiGW.

Dessen, M. A. (2010). Estudando a família em desenvolvimento: desafios conceitos e teóricos. Psicologia Ciência e Profissão, 30(Esp.), 202-219. Recuperado de http://bit. Iy/2OAnBtX.

Diez, J. J. (1982). Familia-escola, uma relação vital. Porto, Portugal: Porto Editora.

Diogo, A. M. (2008). Investimento das famílias na escola: Dinâmicas familiares e contexto escolar local. Lisboa, Portugal: Celta Editora.

Eshetu, A. A. (2015). Parental Socio-economic status as a determinant factor of academic performance of students in regional examination: Acase of Dessie town, Ethiopia. African Educational Research Journal, 3(4), 221-229. Recuperado de http://bit.ly/3rsuJr7.

Fevorini, L. B. (2009). O envolvimento dos pais na educação escolar dos filhos: Um estudo exploratório (Tese de doutoramento, Universidade de São Paulo, São Paulo). Recuperado de http://bit.ly/38k8A6Q.

Lopes, C. M. (2014). Interação família-escola: estudo comparativo entre uma escola pública e uma escola privada (Dissertação de Mestrado). Universidade de Évora.

Marques, R. (1990). A escola e os pais: Como colaborar? Lisboa, Portugal: Texto Editora.

Marques, R. (1994). Colaboração família-escola-estudo de caso. Inovação, 7(3), 357-375. Lisboa, Portugal: Instituto de Inovação Educacional.

Marques, R. (1997). Professores, famílias e projetos educativos. Lisboa, Portugal: Edições Asa.

Marques, R. (2001). Educar com os pais. Lisboa, Portugal: Editorial Presença.

Marques, R. (2002). O Director de Turma e a Relação Educativa. Lisboa, Portugal: Editorial Presença.

Marconi, M. A. \& Lakatos, E. M. (2003). Fundamentos de metodologia científica. São Paulo, Brasil: Editora Atlas S. A.

Martins, A. S. (2008). A escola e a escolarização em Portugal-Representações dos imigrantes da Europa do Leste. Lisboa, Portugal: Editorial do Ministério da Educação.

Oliveira, C. B. E., \& Marinho-Araújo, C. M. (2010). Arelação família-escola: Interseções e desafios. Estudos de Psicologia-Campina, 27(1), 99-108. Recuperado de https://bit.ly/3t0ddec.

Reis, M. P. I. F. C. P. (2008). A relação entre pais e professores: Uma construção de proximidade para uma escola de sucesso (Tese de doutoramento, Universidade de Málaga, Málaga). Recuperado de https://bit.ly/3rtyoVt.

Rocha, I. J. (2009). Envolvimento parental (Dissertação de Mestrado). Universidade da Beira Interior. 
Silva, P. (1994). Relação família-escola em Portugal. Inovação, 7(3), 307-355. Lisboa, Portugal: Instituto de Inovação Educacional.

Silva, P. (2003). Escola-família, uma relação armadilhada - Interculturalidade e relações de poder. Porto, Portugal: Afrontamento.

Sousa, M. M. \& Pereira, M. T. J. S. (2014). A perceção de encarregados de educação e de professores sobre a relação escola-família nas escolas do $2^{\circ}$ e $3^{\circ}$ ciclos de um conselho da região centro de Portugal. Revista eletrónica de educação, 8(2), 321344. Recuperado de http://bit.ly/3qsBasG.

Vilelas, J. (2017). Investigação: O processo de construção do conhecimento. Lisboa, Portugal: Edições Sílabo.

Zassala, C. (2012). Orientação escolare profissional em Angola. Luanda, Angola: Mayamba Editora. 